\title{
RECURSOS NATURAIS NAS PRÁTICAS CASEIRAS DE CUIDADOS A SAÚDE - UTILIZAÇÃO PELA ENFERMEIRA*
}

\author{
Maria Jacyra de Campos Nogueira**
}

\section{POR QUE ESTAMOS USANDO RECURSOS NATURAIS?}

A humanidade parece que só consegue evoluir à custa de movimentos opostos que se sucedem, de tempos em tempos; que, se contrapondo uns aos outros, lançam idéias novas; que, às vezes, retomam e revalorizam idéias antigas, fazendo renascer o que, muitas vezes, já havia sido colocado, de lado, por outros movimentos inovadores.

Apesar do grande avanço alcançado pela ciência no campo da saúde, está havendo, atualmente, um movimento de renascimento de práticas terapêuticas consideradas, como alvorecer da era cientifica e da experimentação, como empíricas, excêntricas e obsoletas.

Por que será que isso está acontecendo? Quais seriam as causas dessa retomada? Por que o homem, depois de ter desenvolvido tanta tecnologia, tanta investigação para cuidar da saúde, passa, de repente, a utilizar-se de práticas baseadas em sistemas empíricos, tradicionais ou antigos?

As causas parecem ser várias. Uma delas, talvez, seja o profundo e confuso sentimento existente nos próprios profissionais de saúde, formados à luz dos conhecimentos cient íficos, contra uma ciência que não conseguiu, tal como sonhavam os antepassados, curar os grandes males da humanidade. $O$ homem, apesar das descobertas que possibilitaram, em alguns casos, até a erradicaçâo de muitas doenças, não conseguiu evitar, em alguns países pobres, a morte prematura de crianças pela fome; esqueceu que a saúde da população depende bem mais das condições do ambiente do que da descoberta do tratamentos de causas etiológicas específicas das doenças; a pesar de pesquisar métodos para prolongar a vida, não foi capaz de conduzir a humanidade ao tão propalado estado ideal de "bem-estar físico, mental e social" ou. simplesmente, tomá-la mais feliz.

* Conferência pronunciada no II Encontro de Enfermagem da Região Norte, promovido pela Associação Brasileura de Enfermagem, seção Pará, Belém (ABEn-PA), abril 1984.

* Enfermeira. Professor Adjunto do Departamento de Enfermagem Médico-Cirúrgica da Escola de Enfermagem da USP - disciplinas Enfermagem Preventiva e Comunitária e Saúde da Comunidade. 
A procura, mesmo por profissionais de saúde, de métodos terapêuticos tão pouco ortodoxos, poderia significar uma reação a essa ciência que lhes trouxe tanto desencanto e frustração.

Uma outra causa tałvez seja a conscientizaçăo desses mesmos profissionais sobre $o$ perigo que representa 0 uso exagerado dos medicamentos industrializados. Embora a descoberta dos antibióticos, dos tranqüilizantes, dos analgésicos e de outros remédios tenha significado uma benção para a humanidade, o seu emprego exagerado, e muitas vezes inadequado, fez com que eles fossem perdendo a sua potência, além de criarem problemas colaterais graves e irreversiveis. As práticas naturais, então, substituiriam, com grande vantagem, pelo menos nas afeç̧ơ banais, esses medicamentos que ficariam restritos somente àquelas doenças mais graves e cuja terapéutica é especifica.

Quanto à populaçio, como explicar esse incremento na procura de métodos terapêuticos considendos por muitos profissionais de saúde como populares ou ñ్ cientificicos?

O uso de terapêutica popular, pelo homem, não é novidade. Todos nós usamos ou usaremos, em alguma época de nossa vida, algum tratamento caseiro aprendido com a familia. A modicin popular sempre existiu, principalmente entres as camadas da populaçáo menos favorecidas economicamente. Para alguns estudiosos, essas classes sociais vivem mais no passado, em termos de práticas de saúde, do que as mais favorecidas. A medicina popular, para eles, nunca foi considerada como paralela à científica, mas originária dela, e provam isso investigando práticas científicas na literatura do pessado e encontrando vestígios dos sistemas antigos nas práticas populares.

O que explicaria o aumento do uso destas práticas, principalmente em nosso País? Em primeiro lugar, um dos fatores que, provavelmente, vêm influenciando essa atitude é, sem dúvida, o preço elevado da assistência médica privada, o alto custo dos medicamentos, além da precariedade da assistência prestada pela maioria dos serviços públicos. A população, então, recorreria à medicina tradicional que, de certo modo, é mais econômica, além de mais acessivel, pois seus "recursos" localizam-se no próprio bairro ou na periferia das grandes cidades, onde as classes mais pobres vivem. Além disso, muitos dos seus agentes fazem parte da própria população e, talvez, tenham mais condiçóes de entendê-la.

Em uma pesquisa realizada em São Paulo entre 1980 e 1983, cujo tema foi a fitoterapia popular, verificaram-se vários aspectos importantes que deveriam ser considerados na prestação de assistência de enfermagem comunitária a populações semelhantes.

O trabalho teve, como objetivos, estudar o conhecimento e o uso de plantas medicinais na terapêutica doméstica e verificar a influência de 
algumas variáveis sociais em relação a esses aspectos. A finalidade foi a de fornecer subsidios para a enfermagem que atua na comunidade, principalmente no sistema de assistência primária. Foram entrevistadas mulheres que freqüentavam os centros de saúde da Região da Grande São Paulo, entre 1979 e 1981 , e verificouse que $86,3 \%$ conheciam plantas medicinais. Dessas, $84,6 \%$ costumavam usar, para si e para sua familia, algum remédio preparado com plantas. A fonte de conhecimento mais freqüente $(86,9 \%)$ foi o meio familial; e o local de aquisição ou origem das plantas mais freqüente $(80,6 \%)$ foi em torno das habitaçoes (quintais e terrenos baldios). As mulheres citaram cerca de 147 nomes vulgares de plantas medicinais que corresponderam a cerca de 131 gêneros. $O$ conhecimento sobre fitoterapia foi influenciado pela idade e escolaridade (as mais velhas e com menos escolaridade sabiam mais) e o seu uso foi influenciado pela idade e procedência (as mais velhas e moradoras na Regiáo, por conhecerem mais as plantas locais usavam-nas mais).

Os motivos para usar as plantas foram vários, sendo os mais freqüentes: "porque gostavam mais, acreditavam mais nelas e achavam que eram mais fortes e nđ̃o faziam mal à saúde" $(50,8 \%)$; "as famnlias sempre as haviam usado" $(22,5 \%)$; "eram mais baratas e mais fáceis de usar" $(17,4 \%)$.

O modo mais freqüente de usar as plantas foi sob a forma de infuso ou decocto, ambos denominados, pelas mulheres, de "cha" $(62,9 \%)$. A parte das plantas mais usada era as folhas $(52,6 \%)$ mas eram tamberm utilizadas raizes, caules, flores e frutos, verdes ou dessecados, puros ou misturados a algum veículo como gorduras vegetais e animais, álcool puro e bebidas alcoólicas, farinhas vegetais, leite, inclusive o humano, sal, açúcar, mel, melado e querozene. Os modos de usar incluem, além dos chás, outros como: aspiração ou inalação, balas, banhos, bochechos, cataplasmas, gargarejos, ingestão como alimento ou como xarope.

As indicaçōes, por ordem de frequeêneia, foram para os problemas relativos a:

- aparelho digestivo $(17,5 \%)$;

- aparelho respiratório e cavidade oral $(15,1 \%)$;

- aparelho genital feminino e obstetrícia $(10,3 \%)$;

- sangue, pele, cabelos, ossos e músculos $(9,2 \%)$;

- doenças transmissíveis da infância e outras $(8,0 \%)$;

- dores, em geral $(6,6 \%)$;

- parasitoses intestinais $(6,5 \%)$;

- puericultura $(6,3 \%)$; 
- sintomas psiconeurológicos $(5,7 \%)$;

- aparelho urinário $(4,8 \%)$;

- olhos $(4,4 \%)$

- perturbaçōes de ordem espiritual $(2,5 \%)$;

- aparelho circulatório $(2,1 \%)$;

- febre $(0,1 \%)$

- outras perturbações $(0,06 \%)$.

Muitas plantas indicadas pelas mulheres contêm principios ativos que foram usados na terapêutica científica de alguns anos atrás e os seus modos de usar também são bem semelhantes, embora tivessem aparecido muitas práticas nocivas à saúde, juntamente com as benéficas.

Foi detectado, nesse estudo, em uma região da periferia da Grande São Paulo, um curandeiro que usava plantas frescas, "garrafadas", benzimentos e que, ao ser entrevistado pelo pesquisador, profissional de saúde, declarou que the daria todas as informaçðes possiveis acerca de plantas medicinais que usava pois "ambos estavam do mesmo lado lutando pela saúde da população"...

\section{O QUE SÃO, AFINAL, OS RECURSOS NATURAIS?}

A natureza é vasta e complexa. O conhecimento do homem acerca dos recursos naturais, que poderiam ser utilizados para a profilaxia e cura dos seus males orgânicos e psíquicos, ainda é muito limitado, apesar dos grandes avanços da ciência e da tecnologia; ainda mais, porque, preconceituosamente, ele muitas vezes só acredita naquilo que vê através da pesquisa científica ortodoxa que tem, por sua vez, muitas limitações.

Parece, entretanto, que as coisas estã่o mudando. Em grandes potências mundiais como os Estados Unidos e a União Soviética, onde os recursos para a investigação são melhores, as pesquisas sobre a natureza do homem, sobre certos fenômenos ligados ao que se denomina, ainda, de paranormalidade, ou de métodos novos para a deteç̧ão precoce de enfermidades, como por exemplo a fotografia Kirlian, têm sido incrementadas nestes últimos anos. $\mathrm{Na}$ China Socialista, ao lado da medicina científica moderna, a energia vital é trabalhada através da acumpuntura, das massagens (Tui-na ou Do-in), de exercícios posturais (Tai-chi-chuan). O restabelecimento do fluxo vital que os antigos tão bem conheciam, modernamente estudado por Wilhelm Reich e, após sua morte por outros cientistas, está presente nas terapias atuais das neuroses que utilizam exercícios, massagens e danças. A terapia de vidas passadas, que se baseia em teorias reencarnacionistas já presentes na antiguidade, procura libertar $o$ individuo de traumas ocorridos em outras 
vidas e estão the causando doenças psicossomáticas, jâ está sendo utilizada por psicólogos e psiquiatras. A musicoterapia tem mostrado terem os sons uma força muito grande nos estados psicológicos, penetrando em níveis profundos da consciência, corrigindo problemas psicológicos graves. A Homeopatia e a Medicina Antroposófica, que têm por objetivo não cuidar da doença mas do ser humano integral, restabelecendo o equilibrio e a harmonia entre suas manifestações orgânicas, mentais e espirituais estão, cada vez mais, conseguindo adeptos entre os médicos mais jovens. Os antigos acreditavam poder o homem captar a luz solar e decompó-la em sete raios que eram absorvidos por cada "chacra" ou regiôes do corpo sutil ou aura, que envolveria nosso corpo físico. Como as doenças se refletem nesse corpo sutil através do desequilíbrio das cores que os constituem, a cromoterapia procura utilizar emissões de energias coloridas para reestabilizar o organismo e curá-lo.

Algumas práticas naturais da medicina tradicional ou antiga ainda estão sendo examinadas seriamente pela Organização Mundial de Saúde (OMS); esta preconiza que sejam feitos estudos, não só para analisar a sua efiććcia, mas também para que sejam incorporados à medicina moderna aquelas comprovadamente eficazes.

Por um tempo demasiadamente longo, os sistemas de medicina tradicional ou antiga ou popular e os da medicina moderna ou cientifica viveram antagonicamente; entretanto, verificou-se que $75 \%$ da população mundial, mesmo nas zonas urbanizadas e desenvolvidas, aceita e usa esse tipo de conhecimento, apesar dos avanços da tecnologia. Esses sistemas, de modo geral baseados em filosofias religiosas da antiguidade, vêm sobrevivendo há séculos, à margem dos movimentos inovadores da ciência, o que demonstra a necessidade que os seres humanos têm deles.

O uso de plantas medicinais, uma forma naturalista de cuidar da saúde, está na moda em todo o mundo. A OMS tem preconizado o uso daquelas que pertencem à cultura popular, após o seu estudo criterioso, como uma das maneiras de evitar o consumo indiscriminado de produtos farmacêuticos. Em todo o mundo estão sendo realizadas pesquisas com plantas medicinais. Os serviços de saúde da China Socialista possuem manuais que descrevem práticas retiradas da medicina tradicional e que utilizam plantas medicinais. No Japão já não se encontram preparados galênicos nas farmácias, mas as plantas medicinais foram aproveitadas pelos grandes laboratorios que extraem delas os seus constituintes terapeuticos, colocando-os, puros, à disposição do público. Na França, existem estudos sistematizados para a valorização das plantas medicinais e na Universidade de Viena estudam-se drogas empregadas há muito tempo na medicina popular. Seis centros localizados em várias partes do mundo estâo colaborando, atualmente, com a Organização Mundial de Saúde, na procura de agentes reguladores da fertilidade aceitá veis, seguros e baratos, de origem vegetal, já tradicionalmente usados pela medicina popular ou tradicional. No México, o estudo da 
medicina tradicional e da flora medicinal tem se desenvolvido muito devido à abundância das plantas empregadas, tradicionalmente, por $40 \%$ da população e devido à riqueza de informação histórica, arqueológica, botânica e tradicional; como os esforços realizados até agora para implantar assistência médico-científica, nesse país, não foram suficientes para atender às necessidades de uma população em crescimento rápido, a medicina popular foi considerada importante e básica para a politica nacional de saúde; 0 Instituto Mexicano para o Estudo de Plantas Medicinais (IMEPLAM) está procurando fazer análise completa de toda a informação relativa a plantas medicinais e seu uso. Os governos de outros países menos desenvolvidos estão adotando esse mesmo critério para lidar com a medicina tradicional e integrá-la na científica e vice-versa.

No Brasil, o Ministério da Saúde, através da Central de Medicamentos (CEME), quer que a população brasileira volte a tomar remédios extraídos da flora medicinal. Por isso está incentivando pesquisas que visam conhecer a eficácia de plantas já utilizadas na medicina popular.

Os profissionais de saúde do País, que estão começando a adotar algumas terapêuticas alternativas naturais, estão começando a se organizar para discutir, analisar e propor métodos mais econômicos e menos danosos para a profilaxia e cura de doenças. Em outubro de 1983, em Uberaba, Minas Gerais, realizou-se o Io Congresso de Medicina Natural. Estudiosos de todo o País se reuniram para discutir, avaliar práticas naturais, novas teorias e meios de captação de energia. A iniciativa, pioneira no Brasil, contou com manifestaçóes de apoio do próprio governo, através do Ministério da Educação e Cultura e do INAMPS. Uma das propostas debatidas no Congresso foi a introdução de disciplinas de medicina natural nas faculdades e $o$ incentivo à pesquisa nesse setor. Durante o evento foi fundada a Associaçáo Brasileira de Medicina Natural, com sede em Uberaba, e já está confirmada a realização de um Congresso em outubro de 1984, em Brasília.

\section{COMO A ENFERMEIRA PODERIA UTILIZAR-SE DOS RECURSOS NATURAIS?}

Em sua III Reunião Especial, realizada em 1972, os Ministros de Saúde das Américas recomendaram que, no decorrer desta década, fossem criados mecanismos que permitissem aos sistemas de serviços de saúde cobrirem toda a população. Esses serviços de saúde, entretanto, só serão realmente abrangentes quando a tenderem não só em extensáo mas, sobretudo, aquelas necessidades básicas mais prementes da população, e quando forem continuamente prestados em locais a que esta tenha realmente acesso.

A consecução dessas atividades de extensão de cobertura, entretanto, constitui-se, todavia, um desafio, principalmente nos países com recursos humanos para a saúde escassos e mal distribuidos como é o caso do nosso País. 
Entre as estratégias propostas atualmente para minorar o problema, salienta-se a implantação de sistemas de assistência primária de saúde, ou de serviços de medicina simplificada, que deverão atender ìs necessidades básicas das populações, inclusive preservando e ajustando, as atividades que, por tradiçâo, já vêm sendo desenvolvidas, como as do sistema comunitário tradicional.

A enfermeira, nesses serviços, é um profissional valiosissimo, embora em muitas áreas ela tenha sido subutilizada, como reconhece a própria Organização Mundial de Saúde. Em relação à medicina tradicional, ela deve manter contacto íntimo com o seu acervo de conhecinentos e seus agentes, e estar aptas para lidar com os mesmos. Em relação à população, terá que prestar assistência efetiva utilizando-se de tecnologia simplificada, econômica, eficaz e bem aceita pela população. Os recursos naturais poderiam ser, entâo, a grande mola impulsionadora dessa assistência .

A enfermagem já dedicou muito tempo às atividades predominantemente orientadas para a satisfação das necessidades de alguns privilegiados; está na hora de, além de ir às periferias, compromissar-se mais com a saúde e menos com a doença; considerar e assist ir ao ser humano de forma integral - corpo, mente e espirito; procurar assisti-lo nas suas necessidades, nâo só biológicas mas também psico-sociais e psicoespirituais; discutir. avaliar, experimentar e usar meios de profilaxia e cura das doenças menos agressivos contra a natureza humana, que ela ainda tão pouco conhect.

A enfermeira, mesmo não exercendo suas funçōes nos já citados serviços de assistência primária, poderá utilizar-se de recursos naturais. De acordo com seu código de ética profissional the é vedado prescrever medicamentos ou ministrá-los sem prescriçâo médica; mas elà nâo necessita desses medicamentos, dessas "balas mágicas", para prevenir. curar ou minorar doenças; ela possui muitas armas ou "remédios" à sua disposição dentro de si mesma, no seu paciente e na natureza ao seu redor; é só tentar conhecer mais a verdadeira Natureza, para saber a quantidade imensa de recursos que terá à mâo.

A enfermeira, é claro, não pode e nem deve deixar de reconhecer o alto nivel de desenvolvimento e a contribuição da medicina moderna, principalmente após o advento dos antibióticos a das técnicas avançadas de cirurgia. A medicina tradicional e as práticas naturalistas, entretanto, precisam ser, também, valorizadas naquilo em que elas possam beneficiar a humanidade.

Antes, contudo, a enfermeira deverá compreender e aceitar conviver, pacificamente, com a medicina tradicional e $\mathrm{com}$ as práticas populares; depois, procurar conhecêtlas melhor, separando o "joio do trigo" para que, com segurança, possa orientar a população sobre jquelas que zao benéficas, neutras ou maléficas; antes de incorporar à assistència qualquer prática, deve 
ainda, procurar conhecer o que cientificamente já foi comprovado em relação a esta; procurar identificar, junto à população, aquelas que fazem parte da sua cultura espontânea, e desenvolver pesquisas experimentais para comprovar sua eficácia e a ausência de efeitos nocivos.

No ambiente doméstico, varios recursos naturais ou práticas naturais podem ser utilizadas, já, pela enfermeira, ou ensinadas a familia. Por exemplo, com relação à alimentação, verifica-se, hoje, principalmente nos grandes centros urbanos, que as pessoas vêm, cada vez mais, substituindo os alimentos naturais, por outros artificiais ou industrializados, com menos nutrientes, com aditivos químicos e mais caros. $\bar{E}$ incrivel a ingestão de refrigerantes e guloseimas (bales, gomas de mascar, etc.) principalmente por crianças, hoje em dia, inclusive pelas mais pobres das zonas periféricas. Muitos profissionais de saúde, inclusive, talvez influenciado pela propaganda, estão incentivando a utilizaçto exagerada desses alimentos e bebidas. Temos observado, por exemplo, em casos de diarrein infantil, que a enfermeira, em lugar de orientar a mé de uma criança para que dê a seu filho um chá de uma planta rica em tanino e sais minerais, como o potássio por exemplo, aconselha - a dar uma marca de refrigerante muito conhecida internacionalmente. A prescriço inadequada e exagerada de uma determinada marca de leite em pó nos centros de saúde beva, muitas vezes, as mães a substituírem o leite materno por esse leite, ma idéia de que ele seja, realmente, o "mais forte, que tem mais vitaminas, sustenta mais e é mais seguro", como responderam algumas mies de uma pesquisa realizada em Sáo Paulo.

Outra área que pode ser bem explorada pela enfermeira é a substituição de medicamentos industrializados usados na autoterapia domestica por recursos naturais como as plantas, ou a energia (calor, cores, massagens, etc.) para a profilaxia e cura de afecçőes banais. A substituiçæ̃o parcial de medicamentos industrializados por plantas medicinais tem sido freqüentemente preconizada como uma das formas de evitar o consumo in discriminado de produtos farmacêuticos. As plantas medicinais proporcionam uma "terapia suave" e apresentam menos desvantagens do que as substâncias puras, mesmo as extraitas do reino vegetal; a sua ação é devida a alguns constituintes elaborados por elas e denominados comumente de "princípios ativos". Além destes, existem outros princípios farmacologicamente inertes, denominados de "ganga vegetal" que muitas vezes agem como coadjuvantes do princípio ativo que exerce; assim, sua ação terapêtica é melhor do que quando o princípio ativo é usado purificado. Por outro lado, além dos problemas introgénicos causados pelo uso inadequado e exagerado, os medicamentos industrializados não passam, segundo estudos, de simples "balas" ou "liquidos de prodigioso sabor", podendo, perfeitamente, devido à sua ineficácia, serem abolidos ou substitufdos por recursos naturais. Além disso a enfermeira sabe muito bem o poder que a mente tem de dominar a matéria e que aquele pode perfeitamente ser utilizado para minorar sintomas de 
doenças ou mesmo para ajudar na sua cura, sejam ou não usadas, as "balas mágicas".

Muitas plantas utilizadas na medicina antiga estão, novamente, sendo usadas, como por exemplo aquelas que tem ação antitérmica, antiespasmódica, cicatrizante, hipotensora, antiasmáticas ou antiparasitárias. É só a enfermeira recorrer à literatura científica atual a respeito do assunto, que estará em conđiçôes de utilizá-las e de orientar a população a usá-las corretamente.

Quanto aos outros recursos naturais, hoje em dia é fácil encontraremse, principalmente nos grandes centros do País, cursos e farta literatura a respeito; é fácil também encontrar profissionais de saúde, inclusive enfermeiras, com experiência em alguns métodos terapêuticos alternativos. Em Sáo Paulo, por exemplo, conhecemos uma enfermeira formada pela Escola de Enfermagem da Universidade de São Paulo, que é acumpunturista, e outra que está desenvolvendo uma pesquisa, também na referida instituição, com um método de massagem rítmica cuja finalidade é aliviar tensões e conseguir a harmonização do Ser. Quanto a plantas, já existem pesquisas realizadas por enfermeiras em várias regiōes do País.

A Escola de Enfermagem da Universidade de São Paulo, neste ano de 1984, irá proporcionar, pela primeira vez, um curso sobre "Terapêuticas alternativas em Enfermagem"; este terá como objetivo a divulgação, para as enfermeiras e estudantes de enfermagem, de algumas práticas terapêuticas naturais que poderão ser utilizadas pela enfermeira na assistência primária.

Aconselha-se às colegas enfermeiras que procurem informar-se sobre cursos e sobre a literatura existente a respeito do assunto para que, em futuro bem próximo, possamos nos aproximar mais da população, assistindo-a mais eficiente, eficaz e economicamente e, ainda, com menor risco.

\section{BIBLIOGRAFIA}

ASSOCIAÇĀO BRASILEIRA DE ENFERMAGEM. Código de Etica do Associậ̉o. São Paub, Subdivisâo de Enfermagem do Hospital das Cínicas da Faculdade de Medicina da Universidade de São Paulo, sd. 1p.

BANNERMAN, R. H. Acumpuntura: a opiniāo da OMS. A Saúde do Mundo, Genebra, 24-29, dez. 1983.

La medicina tradicional en el programa de la OMS. Cron. Org. Mund. Salud. Ginebra, 31(1): 479-480, 1977.

BLAND, J. Uma ciência exata. A Saúde do Mundo, Genebra, 4-10, dez. 1979.

BOLTANSKII, L. Prime educatión et moral de classe. Paris, Mouton, 1969.153p.

BOUISSON, R. As plantas medicinais. A Saúde do Mundo, Genebra, 13-1 7, set. 1983.

CANÇADO, J. Do-in O limro dos primeiros socomos. Vol. 1, São Paulo, Ground, 1981 .126p.e vol.2, Rio de Janeiro, Mantra, 1982.156p.

CEME estimulará o uso de remédios naturais. O Estado de São Paub, São Paulo, 18 nov. 1979.p 25. 
CHERNOVIZ, P. L. N. Formulário e guin médico. 16. ed. Paris, Roger \& Chernoviz, 1897.

CHOU, C. C. O herbário chinês. A Saúde do Mundo, Genebra, 20-23, jul. 1978.

DEXON, B. Além das bahs mágicas. São Paulo, EDUSP, 1981.237p.

DUARTE, D. C. IO Congresso Brasileiro de Medicina Natural. O momento de avaliação das terapias alternativas. Phaneta, São Paulo, (135): 43-48, 1983.

LACAZ, C. da S. et alii. Iatrofarmacogenin. Rio de Janeiro, Guanabara Koogan, 1980.259p.

LANGRE, J. Do-in. Técnica oriental de auto-massagem. 10. ed. Rio de Ja neiro, Ground, 1980.67p.

LA HOMEOPATIA en la actualidad. Foro Mundial, Washington, 4(1): 115-28, 1983.

LOZOYA, X. O equilibrio entre o homem e a natureza. A Saúde do Mundo, Genebra, 8-15, nov. 1977.

MAHLER, H. O bastão de Esculápio. A Saúde do Mundo, Genebra, 3, nov. 1977.

Ação de reforma da enfermagem. A Saúde do Mundo, Genebra, 2-3, dez. 1978.

MEDICINA NATURAL. 1, São Paulo, Editora Três, 1983. 52p.

NETTO, M. O. R et alii. Um estudo sobre aleitamento materno. Rev. Esc. Enf. USP, São Paulo, 12(2): $77-100,1978$.

NOGUEIRA, M. J. de C. Fitoterapia popubr e enfermagem comunitária. São Paulo, Escola de Enfermagem da Universidade de São Paub, 1983.257p. (Tese de Livre-Docência).

Assistência primária: uma responsabilidade da enfermeira brasileira. Rev. Esc. Enf. USP, São Paulo, 17(2): 89-105, 1983.

ORGANIZACIÓN MUNDIAL DE LA SALUD. E papel de $h$ enfermen en hatención primaria de salud. Washington, OPAS, 1977. 15p. (Publicación cientifica, 348).

Extensión de cobertura baseada en las estratégias de atención primaria y participación de b comunidad. Washington, OPAS, 1977.69p. (Documentos Oficiales, 156).

Reunión Especial de Ministros de Salud de Americas. 4. Informe fimal y documento de referencia. Washington, OPAS, 1978.53p. (Documentos Oficiales, 155).

Alma - Ata 1978. Atención primaria de salud. Informe de h Conferencia Internacional sobre Atención Primaria de Salud. Ginebra, 1978.91 p. (Série Salud para todos, 1.)

OSTRANDER, S. \& SCHROENER, L. Experiências psíquicas além đa cortina de ferro. 2. ed. São Paulo, Cultrix, 1970.458p.

PAI-LIN. Curso de Tai-chi-chuan, São Paulo, Missão Católica Chinesa, 1982. (Anotạ̧ōes de aulas.)

PENSO, G. Reencontro com a natureza. A Saúde do Mundo, Genebra, 29-31, jun. 1978.

SOEJARTO, D. D. Plantas para controle da fertilidade. A Sa úde do Mundo, Genebra, 16-19, ago./set. 1978.

XINZHONG, Q. Um tesouro chinês. A Saúde do Mundo, Genebra, 2-3, dez. 1979. 